\title{
Why does Female Underrepresentation Persist in Nigerian Architecture?
}

\author{
Enwerekowe Ebelechukwu Obianuju*, Mangden Daniel Diyenaan
}

Department of Architecture, Faculty of Environmental Sciences, University of Jos, Nigeria

Copyright $\mathrm{C} 2019$ by authors, all rights reserved. Authors agree that this article remains permanently open access under the terms of the Creative Commons Attribution License 4.0 International License

\begin{abstract}
This study aims at examining lingering issues concerning gender in the architectural profession, particularly on underrepresentation and visibility of women in various hierarchies of architectural practice. The findings from a pioneering field study of gender in Nigerian architecture were juxtaposed with literature analysis and summarised reviews of several leading published studies on gender in the profession to provide a quantitative and qualitative assessment of the stumbling blocks for women and the impact of diversity on the outlook of the profession at large. The study identified a trifecta relationship of age, the nature of work done and job satisfaction as impediments to the participation of women which require holistic, all-inclusive, workable solutions for the creation of professional environments made up of diverse perspectives and ideologies. The study recommends: 1) women speak up for what they need from the profession and find active ways to satisfy themselves; 2) equity, equality and diversity in decisions that affect professional growth; 3) willingness to balance families and free time in order to develop professional and personal relationships; and 4) formation of schemes and policies to foster inclusion based on the finding from this and other similar studies.
\end{abstract}

Keywords Architectural Practice, Gender Equity, Holistic Approaches, Underrepresentation

\section{Introduction}

The architectural profession formally opened its doors to include the participation of women towards the end of the $19^{\text {th }}$ century, most of who endured the rigours of exhaustive training and stringent licensing practices in an underrepresented environment $[1,2,3]$. Since then, the profession has witnessed significant (and insignificant) milestones and achievements in the way women are able to participate in, develop and enhance their architectural practices. Growing research interest into the role and effect of gender on architectural training and practice in the last two decades has uncovered many facets to the lingering questions surrounding low female numbers, paucity of female role models and mentors, influence of practice culture and stereotypes, work/life imbalances, personality indexes and persistence of glass ceilings [4-9]. Allusions that differing divergent thinking abilities between males and females can be attributed to gender alone are non-factual: the component factors that affect creative thinking, general intelligence and divergent thinking are more multidimensional than most people think. The influence of gender roles on the manner in which females enter into male-dominated fields, such as design, engineering, science and technology indicate that societal systems are largely to blame for the constraints which suppress, control and sometimes exclude females from professions such as architecture [7].

The general ideology about the practice of architecture as a profession was that it was a very male-oriented profession however it has grown over the centuries from a "male exclusive" unpaid leisure pursuit to a unisex remunerating profession - albeit with significant disparities around the world [10]. Construction is the second most male dominated industry, with women making up just $13.3 \%$ of its workforce overall. While nearly $60 \%$ of women in the industry are employed in traditionally female roles, such as clerical, sales and service roles, a mere $1.6 \%$ of the largest occupational group, tradespersons and related workers, are women. In order to keep abreast with global practice trends in the architectural profession, women are pressured to adopt cultural organisational styles that regard hierarchy, familial teamwork, market demands and adhocracy [11].

Architecture is and always will be an organisational concept dependent on the hierarchical mentor-mentee style of training and eventual practice [12-14], corporate and organisational idiosyncrasies such as glass ceilings and underrepresentation $[15,16]$ and implications on the global outlook of diversity and equity in professional practice $[17,18]$. After decades, female architects have tenaciously come out of obscurity to distinguish themselves in 
architectural endeavours; clinching recognition in the form of distinguished Pritzker, Gold, Aga Khan and Stirling awards which were previously the exclusive honours bestowed on male architects [9]. However understanding why these achievements and the differing circumstances under which these and other similar strides in the profession have (or have not) significantly impacted underrepresentation provides the impetus for this study.

The study closely examines the remote and immediate causes of lingering underrepresentation in the architectural profession, primarily from a domestic standpoint. The study looks at practice trends and patterns as well as practice ideology in the architectural profession from the perspective of domestic and international reports where they exist. Many facts have emerged from recent studies about the participation of women in architecture from obscurity to inclusion in the last century, especially in the last decade. However, much of the reasons why and how women take differing paths to become relevant in the profession remains a mystery. It also remains a bit of a mystery why direct and indirect intervention strategies to increase female participation in the architectural profession have yielded such minimal results in the local setting in which the profession exists today despite global monitoring stratagems. The study addresses speculation that this is as a consequence of more anecdotal rather than empirical studies on the plight of women in architecture which does not foster as much policy change as it does provide entertaining literature. The study questions if those who could make a marked difference in understanding underrepresentation and enhancing diversity hide behind more of a gender-blind and mere lip-service than is realised.

\section{Literature Review: Does Architecture Need Women?}

"...women would find a field for their abilities more particularly in decorative and domestic architecture rather than the planning of buildings 10 to 12 stories high..." - Robert Atkinson, Head of AA School, 1917

The belief that women contributed to certain, not all, aspects of the architectural profession is indeed a deep-seated one. The origin is not unconnected to the most important and challenging issues which have faced feminist movements and studies as they developed into a discipline which has always had the need to recognise, describe, and explain the extent to which there are differences between men and women. As a political practice and academic subject, feminism in many countries has been subjected to criticism as it seems to prioritise the concerns of middle class white western women. There was, until relatively recent years, little regard for other factors (such as race, income, residential standards etc.) which affect the social definition of women and dictate their place in society [19].

During the 1970s and 1980s the development of feminist perspectives emerged as a legitimate area of academic disciplines such as sociology, planning, politics, architecture, engineering and design. This challenged the invisibility of the woman and accentuated the male-centred nature of existing approaches: a discourse on 'feminism', 'women' or 'gender' as key concepts that enjoyed its peak in the early 1990s [20]. Rahder and Altilia [21] note that the use of the word feminist and/or feminism as a key indication of content appears to have declined while the words gender and women have increased in use towards the late 1990s. The content change paved the way for broadened discussion on international and multicultural perspectives of women's issues in almost all fields of study. The ideology of feminist theories transitioned from fighting for equal rights in all spheres (inside and outside the home) to challenging male dominance on leadership roles to the eventual strategic practice of inclusion, diversity and exploration.

The architectural profession remains largely a male-dominated profession by both local and international studies - a finding several recent studies link to downturns in the global economy, restrictive work conditions and poor public perception $[8,9,22-25]$. The general perception held by those inside and outside the profession describes it as being "too heavily male" which promotes a work culture that places too many "demands on a woman's other priorities". Key study findings also include the widespread belief that certain areas within the profession were better suited for women - the "layout design" side, the "softer" side such as residential, interior, green and landscape design - compelling some women to narrow down their field of expertise while they are still in university. The practical work and being the lead architect on site remain sought-after experiences by most female architects but studies have found that for those who work part-time or flexible hours as a lot of women do, this still is not an option. This may explain why it may appear there are not as many opportunities for women as there are for men in architecture [26, 27].

Architecture has a distinctive mentor-based training style which only boosted the inclusion of women in the 1900 's where an architect family member or friend supported the idea of education and professional training for their daughters and became eventual role models: often using those familial ties to secure post-graduation employment into architectural offices for professional practice and in generating a client base [28]. Such collaborations allowed women to remain detached from the 'ego-driven' stereotypical image of the architect by the general public, thus acceptable in most developing countries such as Nigeria where women are still perceived as being socially, culturally, economically and politically inferior to men $[8,11,15,29]$. Time is yet to tell what sort of impact these familial ties, part-time work patterns, 
flexible hours and collaborative work styles of women architects will have on the peak age of creativity (generally in the 50's) and the richness of the profession [22,30]. Particularly since the attrition of women in architecture and the practice challenges they face readily evoke building metaphors such as "a leaky pipeline" and the "glass ceiling" which, despite increasing enrolment in architecture schools in the last 50 years, witnesses flat-lining the higher one moves up the professional ladder. At the top, where the professions highest awards and honours are obtained, participation of women still drops to almost zero.

Looking at the current impression of the status of women in architecture from their first experiences as students to their climb up the professional ladder presents a clear image of why they are still underrepresented and often have slower practice development in recent years. Poor work-life balance, pay disparity, incompatible work culture, employability, recession, lack of mentors and role models, client perception, discrimination and sexism (more on site than in an office) and definitive gender roles have been the long-held deterring factors for women in architecture [31, $22,19,23,32,8,9]$. Updated findings include female apathy (particularly during the years of training and registration), sheer lack of interest or desire to progress and misinformation to prospective entrants into the profession which challenges not only the perspectives on why women struggle to enter and stay in the profession but also why they would pursue it at all $[33,22,26,34]$.

Consequentially there have been several recommendations for boosting the participation and progress of women in the profession based on the observations and justifications raised in the studies though the results have been mixed. Direct and indirect intervention incentives to boost professional registration has witnessed marginal improvement in the number of women who seek to register when they first graduate but made little impact among the many talented women who have staggered work patterns due to family responsibilities [35]. Women, who still constitute less than $20 \%$ of registered architects and $10 \%$ of practice partners globally are still discouraged by the low pay and/or pay disparity between men and women in the profession despite equal qualification. Husband-wife partnerships have boosted better work-life balance which permits each member the ability to find and retain significant work opportunities upon returning to the industry after taking time off to start or raise a family. Women who do not have the benefit of such partnerships agitate for improved mentorship and support groups, more accommodating work culture and increased job flexibility which include the option to work remotely, job share, or work flexible hours [26]. Professional bodies have been tasked with the responsibility of doing more to tackle the gender imbalance and improve the retention of women within the industry [23].

Consistent recommendations suggest there is a place for women in architecture. Understanding and appreciating the legacy, contributions and determination of the likes of Louise Blanchard Bethune, Joan Goody, Denise Scott Brown, Anna Keichlire, Ada Louise Huxtable, Julia Morgan, Zaha Hadid, Chinwe Abulokwe Ohajuruka and Jumoke Adenowo explains why the profession needs and thrives with the inclusion of women [1, 36-39]. Therefore, examining recurrent and developing problems in the participation of women in architecture primarily in Nigeria as a developing nation is the main focus of this paper which draws its conclusions from the juxtaposition of recent findings of local and international origin.

\section{Materials and Methods}

This study was carried out as a qualitative review of a mixed-method study which combines literary research, a survey in Nigerian architecture and quantitative data analysis. Literary research covered the review of existing knowledge and developing issues concerning women in architecture and supplied the data for analysis from published reports generated by international professional bodies such as the RAIA (2007), RIBA (2012), AACA (2015) and AIA (2016). The field studies gathered responses from a 2012-2016 pioneering gender-based study of the practice of the architectural profession within Nigeria on practice participation, nature of work done and job satisfaction as a bottom-up approach to a qualitative and quantitative analytical process [40]. The central study from Nigeria sampled 183 respondents (81 female, 102 male), in excess of the statistically determined minimum sample size of 60 respondents per gender derived from the 2-step Moser-Kalton formula. At the time of the data collection, the study identified that there were 4,504 registered architects in Nigeria of which only 410 were identified as female (representing just $9 \%$ of the population). The national professional bodies had no historical records of their members classified by gender. In both the primary and the secondary studies, questionnaires were distributed through architectural practice databases and returned via email and online portals ensured far-reaching audiences and high response rates of between $71-86 \%$ which satisfies benchmark response rates deemed acceptable for analysis [41-44]. The sample sizes were statistically determined to be above $5 \%$ of the target populations in conformity with standard derivation techniques [45]. An additional method of primary data collection was the use of interviews which were conducted among selected persons of interest based on the responses in the questionnaire stage. The survey and published reports represent recent, and in some cases, last known findings on underrepresentation in the architectural profession in their individual contexts and highlight recurring and fresh issues in professional satisfaction. The data is presented and analysed using pictographs, tables 
and descriptive analysis. This study then attempts to identify trends that persistently undermine efforts to boost the participation and development of women in architecture.

\section{Results and Discussion}

Cross examination of the many issues and trends on gender in the architectural profession in past and on-going research repeatedly draws attention to a few central themes at the heart of discontent on underrepresentation and diversity. A trifecta of factors - each driven by additional influences - appear universally as recurrent themes in gender studies in architecture which are responsible for the low number of women in the profession in Nigeria, especially in active practice roles and at high ranking levels. Each of these main factors and their supporting influences will be discussed in this section of the study and conclusions on remediation strategies will be offered in the subsequent section. Parallel findings from published international studies substantiate the discussions on the issues raised and recommendations that arise from the study. The 3 (three) pertinent identified factors from the primary data are: age, nature of work done and job satisfaction.

\subsection{Age}

This understated yet significant factor affecting the participation of women in the architectural profession comes to the forefront as a result of the parallels drawn from the primary survey data and the studies under review. Nearly two-thirds of the women who responded to the surveys were below the age of 45: a significant age for women who are still keen on child-bearing in developing countries like Nigeria (Figure 1). In such circumstances, child-bearing (and extended nurturing since women are seen as primary care-givers until children reach adulthood) plays an integral role in fulfilling one of the major requirements of women in African society. However this responsibility impinges on the professional development of women architects in Nigeria where birth rates (of women aged 16-40 years old) are very high.

The process of becoming an architect does not end upon training completion from a formal institution. Rather, that stage is merely the beginning of the journey. Any architect wishing to become a registered professional must complete a lengthy (and often times expensive) licensing process which is predicated on a specified number of years of practical work experience prior to completing the licensing and certification program. The data underscores a strong link between the age of the woman and the amount of practical work experience needed to prepare for the licensing procedure which is a critical pre-condition to practicing as an architect. Domestically an architect preparing for the licensing exam requires a minimum of 2 (two) years post-qualification full time work experience. Comparatively in Australia, the minimum requirement is 3300 hours which is up to 5 (five) years for full-time worker.

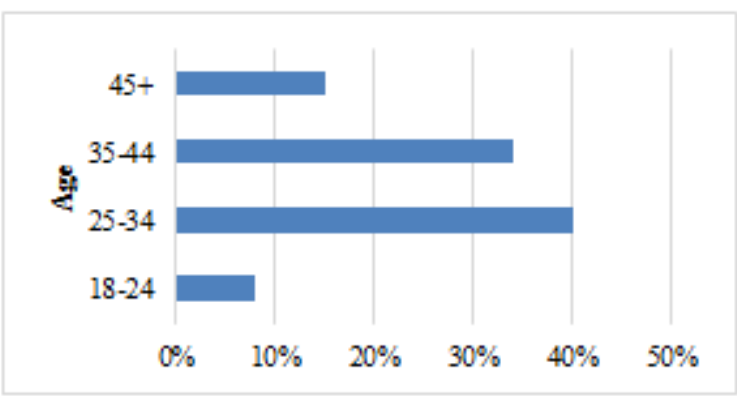

(a)

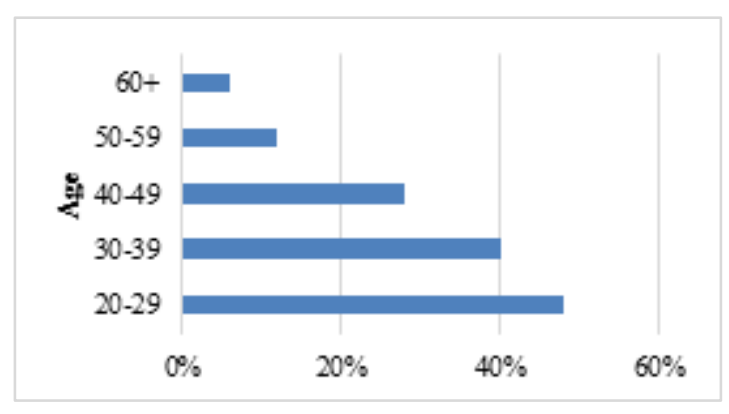

(b)

Figure 1. Age of women architects in (a) Nigeria and (b) Australia Sources: $[8,35]$

For the woman architect who may find herself engaged in staggered work patterns due to family commitments, this minimum post-qualification benchmark may just be all too elusive. This results in a longer wait for most women to get registered. Women in Nigeria have come to expect (and accept) delayed gratification in the build-up to professional certification because of their societal role as child-bearers and care-givers. However the findings show inconsistencies in the popular belief that every woman who is an architect has the uncontrollable desire to breed despite her career goals. Nearly $65 \%$ of the women in the surveys had children with spouses or practice partners who shared increased parental responsibilities and more than half extolled the benefits of external child care services (including accepting assistance from extended family members or engaging domestic help) for nurturing children. This upholds the age old African adage that "it takes a village to raise a child". Nearly two-thirds of the women in the survey commended a delay in the process of having children until such a time when significant progress had been made in professional development. This is a practice recommended for many women at point of graduation and architectural practice registration in recent years in Nigeria and implemented by nearly $17 \%$ of the women respondents in the survey. On the other hand, while practice 
partnerships have been known to ease the burden of the licensing procedure, the outcome is usually less favourable to the woman. In nearly $37 \%$ of the husband-wife partnerships observed, women admitted to living vicariously through the work of their partner or spouse, leading to the development of the "starchitect" (star architect) who is more renowned.

Thus, the discord between requisite years of work experience and a woman's biological clock (which is more or less consequent on her age) explains the drop in the number of women getting licensed compared to the number of women leaving school (Figures 2 and 3). This finding is buttressed by the qualitative responses from the surveys showing that women take, on average twice as long as men to gain the necessary work experience required for licensure resulting in direct and indirect age discrimination when they return to the work place after taking time off to raise children.

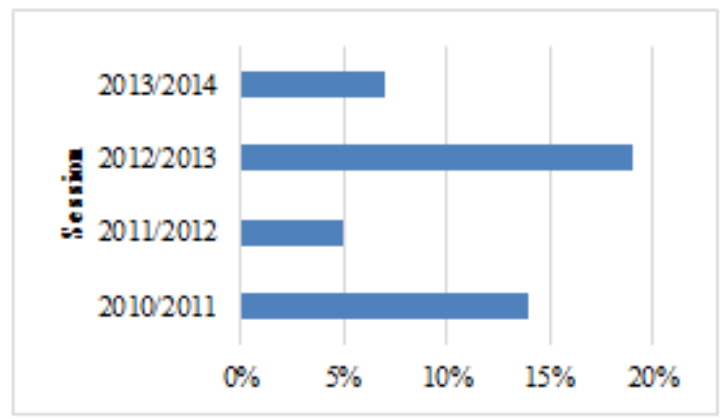

(a)

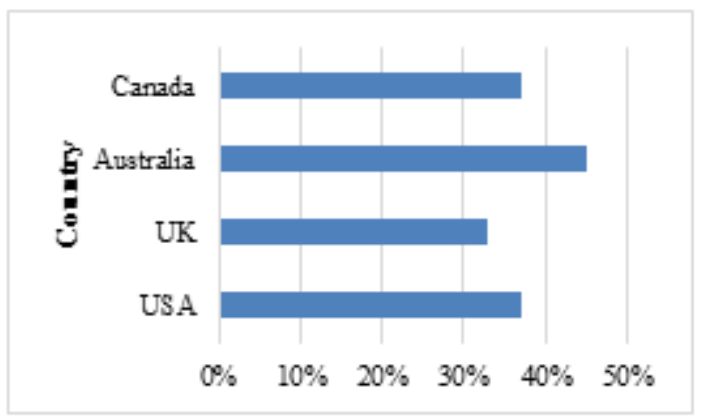

(b)

Figure 2. Number of women graduates from architectural programs in (a) Nigeria and (b) international averages (2005-2015) Sources: [8, 46, 47]

In widely accepted literature, most architects hit their creative peak in their 50's. Another consequence of the age of a woman on architectural practice participation is the inability of women to competitively attain this milestone at the same time as the men. Women are perceived to be less driven in developing creative prowess and career goals if they "...go off to have babies all the time..." as one male employer puts it in an interview: an apprehension about employability after taking time off held by about $75 \%$ of the women sampled in the survey. Such perceptions (true or false) have a significant impact on the number of women who enter into and continue in the architectural profession as corroborated by several leading international studies. A number of helpful tips from women in the profession recommend the willingness to compromise with families and their free time which not only helps with balancing the profession and family but also encourages networking. Learn how to play golf or tennis. Sign up for service organisations such as Rotary or PTA. Being visible in both professional and social networks has been known to foster promotion and job progression, especially with flexible work patterns. In other words, each woman needs to "find her own way" through the formative years which favour men as they dictate career paths.

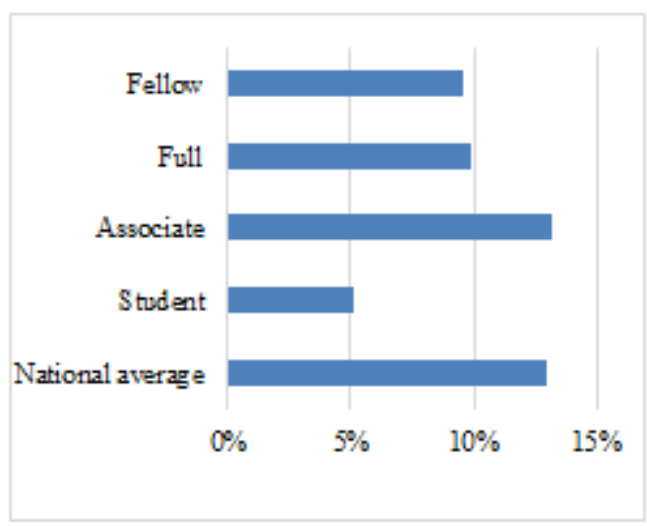

(a)

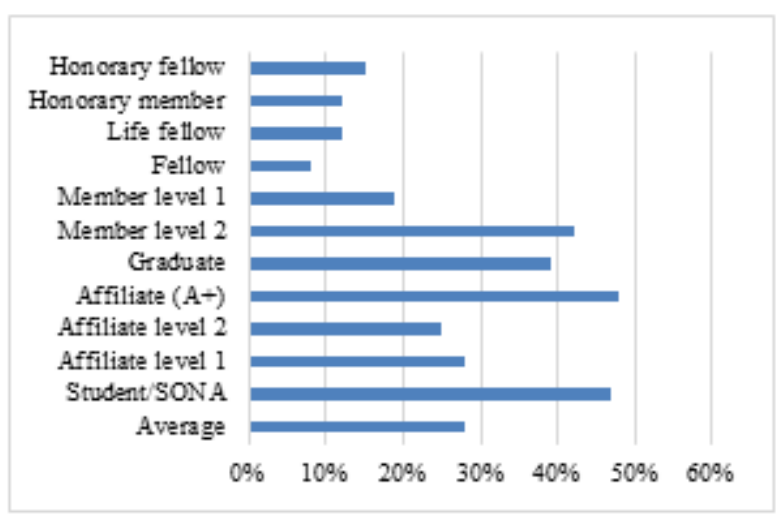

(b)

Figure 3. Average number of women licensed to practice architecture in (a) Nigeria and (b) Australasia per annum. [Sources: 8, 28]

\subsection{Nature of Work Done}

The findings from both local and international surveys shows women still make up only $15-18 \%$ of architectural partnerships with an increased move from design/build firms into the academia in the both public sector (from local findings) and the private sector (from international data) as shown in Figure 4. Less than 2\% of those women go on to become senior management in practice or occupy top level positions in their establishments. Those not 
prepared for life as an academic opt for setting up one-person firms or small scale family partnerships that deal largely with multi-family and single-family housing projects and additions. Women who remain in the larger, multi-partner firms often find themselves relegated to non-competitive aspects on design project teams or are required to act as a "back up secretary" expected to take "phone calls and make coffee". Many women from the Nigerian survey voiced concerns about the nature of work suitable to encourage a healthy work-life balance which many respondents still struggle with: a finding similar to studies on architectural practice development from the UK and Australia. The study findings through the interviews however revealed concerns that "suitable" work (most of which does not extend beyond small- or medium-scale "human interest projects") is not always the best for career progression or creating rewarding or challenging opportunities.

The findings from the survey seem to suggest that there are several discouraging influences that affect the choice of work done, some of which include direct or indirect discrimination based on age and/or gender, limited work opportunities and non-progressive work trends, lack of respect for the role of the architect, pay disparity and elongated working hours. Qualitative findings from the survey indicates that $83 \%$ of women would forgo a job opportunity if it did not afford a reasonable amount of flexibility, the opportunity to progress both personally and professionally, the ability to leave behind an impressive body of work and obtain a reasonable amount of financial reward. For most women, this selective approach often limits the type of work available upon graduating from college and does little to encourage increased participation or raise the status of women in the profession. Suggestions from the 2005-2007 and 2015 studies by the RAIA in Australia on this theme seem to indicate that women are less likely to be involved in challenging architectural work simply because they do not aspire to which could ultimately lead to their undoing. During times of economic downturn (as is experienced across the world lately), those who work under such discriminating circumstances are the first to be let go or face lay-offs.

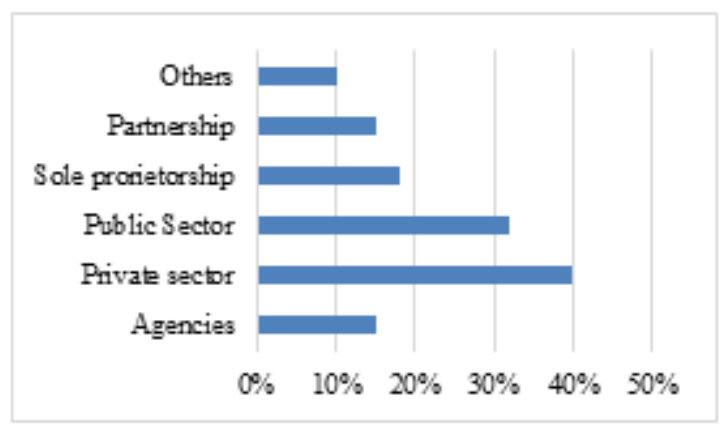

(a)

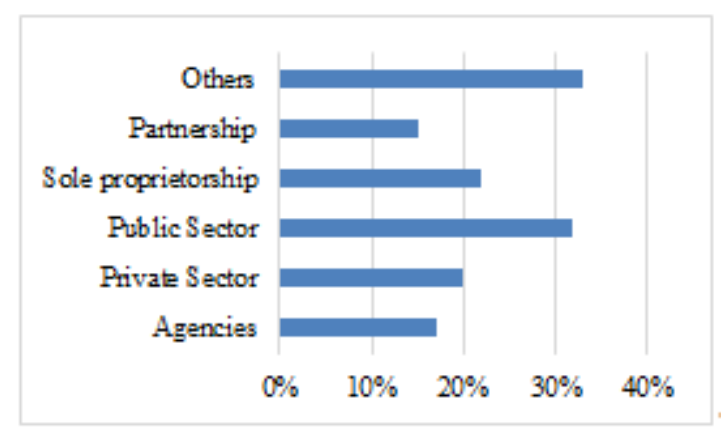

(b)

Figure 4. Average nature of architectural work done by women in (a) Nigeria and (b) international conditions (2013-2015) [8,28]

Another consequence of the nature of work done is the absence of role models and mentors in certain organisational models. Selective or discriminatory work conditions make it more difficult to find like-minded mentors and this phenomenon is more apparent in the case of sole practitioners. How do they build support groups? Where do they find and associate with mentors and role models? Do they face further risk of isolation or segregation by working outside multi-partnership models which offer inflexible work patterns? Most of these challenges could be overcome by volunteering or mentoring in a support network. Nearly $25 \%$ of respondents in the local study opined that the profession requires better mentoring schemes and training programs (especially for women), $22 \%$ supported additional role model development and 31\% lobbied against industry discrimination.

\subsection{Job Satisfaction}

Job satisfaction is a highly recurring theme in most studies about professional diversity and perhaps holds the key to understanding the high departure trends and underrepresentation that characterise the architectural profession in recent years. Most indices of assessment point to low levels of job satisfaction with a number of factors that influence the departure and retention of members. Findings from the observed case studies indicate that $12 \%$ of all women change their career path after graduation from architecture school. The departure rate in Nigeria hovers between 13-25\% annually. An additional 22\% sought to leave architecture or take on less demanding responsibilities within 5 years of post-qualification. This presents a challenge to a profession that still boasts less than $20 \%$ female participation in local and international instances. The most popularly cited reason for the abandonment of the profession is job dissatisfaction: especially with regards to disillusionment and disappointment from the expected rewards for the effort put into personal and professional development in the architectural profession. 
The findings on Tables 1 and 2 reveal the shrinking differences between the level of satisfaction of men and women in local and international studies. Comparatively, overall levels of job satisfaction between genders have become less distinct over the years although men are slightly more satisfied with key aspects of the profession than women. Remuneration remains the least satisfactory aspect of the profession which is not necessarily a gender specific issue - over $70 \%$ of the women in international reports citing pay disparity and devaluation as leading causes for concern in the international case studies, a not-so pressing concern in the Nigerian scenario. There are no observable structural pay differences between the genders of equal training and experience in private or public service but there were differences in the ways in which men and women secure remuneration for architectural services in Nigeria. Women have less bargaining power than their male counterparts and are three times more likely to accept a reduction in the approved scale of fees under negotiation with a client. Women are expected to concede more else they are considered "pushy" or "aggressive". Perhaps even a bit too masculine. This situation appears to worsening due the public perception about the diminishing role of the architect in the society among all the allied professionals in the built environment. The inability to handle meaningful projects is also a source of discontent among the respondents to the survey and this has led to the establishment of more sole practitioners who enjoy more control over the type of work done and the nature of remuneration.

From qualitative findings, there were some positive reactions to job satisfaction from some women respondents who found that there were "benefits" from working in male dominated firms which included being the "only member on the team who brought a 'softer, human side' to the design of residential spaces" or adding a "special woman's touch" that men do not have. Some of the women respondents found satisfaction in the balance of personal and professional goals but this is consequent on the availability of supportive maternity laws and flexible work options. Despite these standalone assertions, the findings over the years consistently show that $45-55 \%$ of women withdraw from mainstream architectural practice due to dwindling job satisfaction.

Table 1. Satisfaction with the architectural profession among Nigerian men and women [8]

\begin{tabular}{lcc}
\hline Job satisfaction indices & \multicolumn{2}{c}{ Level of satisfaction } \\
\hline & \% male & \% female \\
\hline Opportunities to improve skillfully & 55 & 49 \\
\hline Remuneration packages & 39 & 35 \\
\hline Organizational culture & 47 & 40 \\
\hline Work-life balance & 52 & 40 \\
\hline Professional development & 57 & 46 \\
\hline Handle meaningful projects & 51 & 36 \\
\hline Recognition for job done & 59 & 47 \\
\hline Job security & 55 & 56 \\
\hline Flexibility & 60 & 59 \\
\hline
\end{tabular}

Table 2. Satisfaction with the architectural profession among men and women in the US [26] and Australia [22]

\begin{tabular}{lcccc}
\hline Job satisfaction indices & \multicolumn{4}{c}{ Level of satisfaction } \\
\hline & \% male & \% male & \% female & \% female \\
\hline Opportunities to improve skillfully & 54 & $\boldsymbol{R A I A}$ (2007) & $\boldsymbol{A I A}$ (2016) & $\boldsymbol{R A I A ~ ( 2 0 0 7 )}$ \\
\hline Remuneration packages & 46 & 57.2 & 45 & 64.9 \\
\hline Organizational culture & 53 & 42.1 & 34 & 40.9 \\
\hline Work-life balance & 49 & 50.0 & 48 & 48.9 \\
\hline Professional development & 55 & 51.8 & 45 & 50.2 \\
\hline Handle meaningful projects & 48 & 48.5 & 48 & 47.6 \\
\hline Recognition for job done & 48 & 50.3 & 39 & - \\
\hline Job security & 56 & - & 42 & - \\
\hline Flexibility & 39 & 70.9 & 53 & 75.8 \\
\hline
\end{tabular}


As discussed in earlier sections of this paper, the demands of the profession at entry, training and licensure deter a lot of women from architecture. As many as half the respondents in the study advocated for a licensing process that takes into consideration the challenges women face and it is a valid recommendation that they assess the value of being an architect (with the workload, stress, low pay etc.) before committing to the profession indefinitely. In the last decade, architecture graduates have recorded the highest unemployment rates among all the professions including medicine, law, engineering and accounting. Post-qualification success depends largely on building a portfolio and client base which in turn leads to future commissions and awards. This repeatedly raises questions about the visibility of women architects and the way they are able to build their practices. One account is that women, particularly Nigerian, disappear or become invisible in the profession because they are offered fewer opportunities to make their voices heard. Young men, on the other hand, are encouraged, praised, nurtured and offered numerous opportunities and experiences which place them on the path towards registration without the stumbling blocks women face. From the same source, it was observed that women (particularly those with families) are less geographically mobile than their male counterparts and this often frustrates the opportunities to "follow the work". This suggests that women appear to have a different attitude about work than men do which may be a result of discrimination against them or a combination of this, life choices and career changes in the profession. The big question about these weighted considerations is this: what should they do about this?

\section{Conclusions and Recommendations}

In a profession where there is little or no practice of diversity in terms of gender, there tends to be a very little room for drastic changes as the culture of the profession limits a lot of ideas coming from the supposed minority. The study highlighted issues that are responsible for the underrepresentation of women in architecture which are synonymous with most of the challenges not far removed from the universal themes in gender studies. Not just that women are underrepresented in the profession, within the profession itself, a great proportion of women are clustered in the lower ranks of the profession and as you go higher, there is a deep decrease in their population. Architecture is not and should not be considered only a "gentleman's profession" because there are many women out there who love the profession for how it embraces a variety of disciplines: design, geometry, history art and social behaviour.

The females formed the minority in every aspect of the study. From their graduation to their field work, the results of the findings show that the structure and culture of the profession clearly do not suit a woman and her person. Women continually find themselves excluded from the vital networks and experiences for professional growth in Nigerian architecture which resonates with women in the profession from around the world. The need to stress for personal and professional balance addresses concerns about the increasing number of women who pick interest in studying architecture and lose interest in staying in the profession once the practice becomes unfavourable.

The study observed that at various stages of the professional ladder there has been gross underrepresentation in all phases in both local and international contexts. From the survey and the various studies examined here, it is clear that the first step towards addressing the issue of underrepresentation in architecture would be a proactive reset of the thinking behind the profession. The distinctions between men and women are clear but the future (and success) of the profession depends on the understanding that all players are part of the same team. Entry requirements for training, licensure and progression mandate equity and equality for all genders in order to establish and maintain the diversity the profession desperately needs. No one gender needs to be more visible than the other, neither does one deserve to be disadvantaged by the other. The architectural profession provides work that is a privilege, personal, fun and satisfying if given the proper leeway: architecture allows for one to explore countless career directions.

This study therefore recommends that women in Nigerian architecture learn how to ask for what they need from the profession. In order to maintain equity, equality and diversity in the profession, there is the need for regular and on-going public awareness initiatives by stakeholders in the profession on the role of architects in society, particularly the women. Likewise, the study suggests willingness to find the middle ground between family and free time in order to cultivate the necessary professional and personal relationships that support practice retention and drive career progression. The delicate work-life balance challenges many African societal norms, particularly in child-bearing and raising but is necessary to address the key variables affecting the increased participation of women in Nigerian architectural practice. Architecture allows for one to go in limitless career directions. The study also recommends programs and incentivised schemes for architects in training about what it takes to become an architect (especially as a woman), the challenges they may face in practice and how to handle such challenges without compromising with the professional standard. This is pertinent to the formation of policies that foster inclusion and boost retention among women in the profession as till date there are no initiatives of any sort in Nigerian architecture to address underrepresentation of women despite the increasing body of evidence requiring attention. 


\section{REFERENCES}

[1] A. Barbasch (1989). Louise Blanchard Betheune: The AIA accepts its first woman member. In E. P. Berkeley, M. McQuaid (Eds.). Architecture: A place for women (pp. 15-25). Washington, USA: Smithsonian Institute Press.

[2] L. Hall (1989). A pivotal group in Architecture: The fourteen women of MIT, Class of 1930. In E. P. Berkeley, M. McQuaid (Eds.). Architecture: A place for women (pp. 79-86). Washington, USA: Smithsonian Institute Press.

[3] E. G. Grossman, L. B. Reitzes (1989). Caught in the crossfire: Women and architectural education, 1880-1910. In E. P. Berkeley, M. McQuaid (Eds.). Architecture: A place for women (pp. 27-39). Washington, USA: Smithsonian Institute Press.

[4] J. Baer (1993). Creativity and divergent thinking: A task specific approach. Hillsdale, NJ: Erlbaum.

[5] H. Reese, L. Lee, S. Cohen, J. M. Puckett (2001). Effects of intellectual variables, age, and gender on divergent thinking in adulthood. International Journal of Behavioural Development, 25(6), 491-500.

[6] K. Anthony (2008). Designing for diversity. Urbana, Chicago, USA: University of Illinois Press.

[7] A. A. Potur, O. Barkul (2009). Gender and creative thinking in education: A theoretical and experimental overview. ITU $A-Z, 6(2), 44-57$.

[8] E. O. Enwerekowe (2016). The effect of gender on the practice of the architectural profession in Nigeria. (Unpublished doctoral thesis), Department of Architecture, University of Jos, Plateau State, Nigeria.

[9] O. A. Fulani (2017). Gender issues in the learning of architecture in private universities in Ogun state, Nigeria. (Unpublished doctoral thesis), Department of Architecture, Covenant University, Ota, Ogun state, Nigeria.

[10] L. Walker (2012). Women architects in the early 20th-century. England: English Heritage, UK.

[11] A. A. Oluwatayo, D. Amole (2012). Culture of Architectural Firms in Nigeria: An exploratory study. Journal of Construction in Developing Countries, 17(2), $1-21$.

[12] A. J. Willis, W. N. B. George (1981). The architect in practice ( $6^{\text {th }}$ edition). London, UK: Granada Publishing Technical Books Division.

[13] J. Evetts (1996). Gender and career in science engineering. London, UK: Taylor and Francis Publishing.

[14] K. Burns (2012, August 28). Women in architecture. Parlour: women, equity, architecture. [Web log post] Retrieved fromhttp://www.archiparlour.org/women-and-ar chitecture.

[15] J. K. Obamiro, K. Obasan (2013). Glass ceiling and women career advancement: Evidence from Nigerian construction industry. Iranian Journal of Management Studies, 6(1), 77-97.

[16] V. Singh (2013, May). Think article: Women and the glass ceiling. Retrieved from http://www.som.cranfield.ac.uk/so $\mathrm{m} /$ somapplications/somapps/contentpreview.as?pagd $=132$ 73\&apptype $=$ thinks \& article $=217$.

[17] C. Iztin (1995). The gender culture In Gender culture and organisational change: Putting theory into practice. London: Rutledge Press.

[18] M. Blair-Loy, L. Pecenco, E. Cech (2013). The persistence of male power and prestige in the professions: Report of Law, Medicine, and Science \& Engineering: Final report. Centre for Research on Gender in the Professions. UC San Diego, USA. Retrieved from http://crgp.ucsd.edu.

[19] A. Gregory (2009, August). Calling all women: Finding the forgotten architect. Retrieved from http://blog.aia.org/aiarc hitect/2009/11/calling_all_women_finding the.html.

[20] L. Ginzberg (2002). Re-viewing the first wave. Feminist Studies 28(2), 419-434.

[21] B. Rahder, C. Altilia (2004). Where is feminism in planning going? Appropriation or transformation? In Planning Theory, 3(2), 107-116.

[22] Royal Australian Institute of Architects. (2007). The career progression of men in architecture. Melbourne, Australia: Author.

[23] Royal Institute of British Architects. (2008). Why do women leave architecture? Retrieved $28^{\text {th }}$ August 2012 from

http://ww.architecture.com/TheRIBA/AboutUs/Influencing Policy/Poli

[24] K. Rosenfield (2014, January 4). Studies show architecture graduates with highest unemployment rates. Arch-daily online. Retrieved from http://www.archdaily.com/?p=1973 51.

[25] E. O. Enwerekowe, J. O. Abioye (2018a). Challenges to job security of female architects in Nigeria. International Journal of Innovative Research and Advanced Studies, 5(7), 103-110.

[26] American Institute of Architects (2016). Diversity in the profession of architecture. Washington DC, USA: Author.

[27] E. O. Enwerekowe, J. F. Abioye. (2018b). Clients perceptions about the synergy between architects and allied professionals in the Nigerian built environment. Journal of Environmental Sciences and Resource Management, 10(4), 65-82.

[28] D. D. Mangden. (2017). Women in Architecture: The challenges they face as they climb the Architectural ladder in Nigeria (Unpublished baccalaureate thesis), Department of Architecture, University of Jos, Nigeria.

[29] E. O. Enwerekowe, J. D. Tsok (2017). Performance assessment of sustainable architectural practices in Nigeria: Insights from the diminishing role of the architect. Journal of Applied Sciences and Environmental Sustainability, 3(8), 123-140.

[30] R. Waite, A. Corvin (2012, January 16). Shock survey results as the AJ launches campaign to raise women architects' status. Architects Journal (AJ) Online. Retrieved from www.architectsjournal-co-uk.pdf.

[31] A. De Graft-Johnson, S. Manley, S. Greed (2003). Why do women leave architecture? Bristol, England: University of the West of England.

[32] E. Enwerekowe, E. Ola-Adisa (2015). Gender perceptions of skill sets of female architects in North Central Nigeria In S. Laryea, R. Leiringer (Eds.) Proceedings of $6^{\text {th }}$ West 
African Built Environment Research (WABER) Conference (vol. 2), $10^{\text {th }}-12^{\text {th }}$ August 2015, Accra, Ghana, pp. 611-622.

[33] G. Matthewson, K. Volz, N. Stead. (2013). Women's involvement in the Australian architecture profession: Building a clearer and more inclusive picture (Draft report). Commissioned by the Australian Research Council for the Steering Committee of the National Council of the Australian Institute of Architects, University of Queensland and University of Melbourne, Australia.

[34] E. O. Enwerekowe (2018). Attitudes towards design studio culture and the expected learning outcomes in Nigerian schools of architecture. In G. Azare, S. B. Arokoyo, C. B. Amough (Eds.), Reforms and innovation in Nigerian education: The journey so far (pp. 1-14). Onitsha, Nigeria: West and Solomon Publishing Co. Ltd.

[35] Architects Accreditation Council of Australia (2015). Industry profile: The profession of Architecture in Australia. Melbourne, Australia: Author.

[36] D. S. Brown. (1989). Room at the top: Sexism and the star-system in architecture. In E. P. Berkeley, M. McQuaid (Eds.). Architecture: A place for women (pp. 237-246).Washington, USA: Smithsonian Institution Press.

[37] R. Martin (1989). Out of marginality: Towards a new kind of professional. In E. P. Berkeley, M. McQuaid (Eds.). Architecture: A place for women (pp. 229-235). Washington, USA: Smithsonian Institution Press.

[38] Rizzoli (2009). Zaha Hadid: Complete works. New York, USA: Rizzoli International Publications Inc. - Author.

[39] S. Stephens (2014). A woman for all reasons. Architectural Record (May), pp. 58-65.

[40] V. J. Duriau, R. K. Reger, M. D. Pfarrer (2007). A content analysis of the content analysis literature in organisational studies: Research themes, data sources and methodological refinements. Organisation Research Methods, 10, 5-34.

[41] J. Buglear (2001). Stats mean business: A guide to business statistics. Burlington, USA: Butterworth Heinemann (of Elsevier Publishing Ltd).

[42] A. J. Onwuegbuzie, M. K. T. Collins (2007). A typology of mixed method sampling designs in social science research. The Qualitative Report, 12(2), 281-316.

[43] J. E. Fincham (2008). Response rates and responsiveness for surveys, standards and the journal. American Journal of Pharmaceutical Education, 72(2), 1-3.

[44] Z. A. Uji (2009). Tool and instruments of research in design and applied disciplines. Jos, Nigeria: Ichejum Publishing House.

[45] A. Crossman (2017). Understanding your purposive sampling: An overview of the method and its application. Retrieved from https://www.thoughtco.com/purposive-sam pling-3026727.

[46] Higher Education Statistics Agency. (2005). Last update: All higher education students by subject of study, domicile and gender 2004-2005. Retrieved from www.hesa.ac.uk/holisocs/pubinfo/stud.htm.

[47] National Architectural Accrediting Board. (2015). Report on accreditation in architectural education. Retrieved from www.naab.org. 